\title{
SISTEM INFORMASI GEOGRAFIS PADA APLIKASI DESA PINTAR BERBASIS MOBILE
}

\author{
Gresa Pranata Simarmata, Fati Gratianus Nafiri Larosa ${ }^{\bowtie}$, Jimmy Febrynus Naibaho
}

Fakultas Ilmu Komputer, Universitas Methodist Indonesia, Medan, Indonesia

Email: fatignlarosa@gmail.com

DOI: https://doi.org/10.46880/jmika.Vol4No2.pp179-185

\begin{abstract}
The villages in the Andam Dewi sub-district, Central Tapanuli have not maximally utilized information from the Central Bureau of Statistics (BPS). The information obtained using Google Maps is still standard and does not represent the potential of the villages in the sub-district. One of the efforts to further encourage the economy is to encourage the development of villages based on local wisdom, natural resources, and their uniqueness so that they can become innovative and creative villages. The Geographical Information System in the Mobile-Based Smart Village Application was created to make it easier for the government, community, tourists, and potential investors to find information on village potentials such as fisheries, plantations, trade, tourism, culture, and public services. This system is built using the PHP and Java programming languages and MySQL as the database. The result of this research is a mobile-based geographic mapping application.
\end{abstract}

Keyword: GIS, Smart Village, Central Bureau of Statistics, Mobile.

\begin{abstract}
ABSTRAK
Desa-desa yang berada dalam kecamatan Andam Dewi, Tapanuli Tengah belum maksimal dalam memanfaatkan informasi dari Biro Pusat Statistik (BPS). Informasi yang diperoleh jika menggunakan Google Maps masih bersifat standar dan kurang menampilkan potensi desa-desa di kecamatan tersebut. Salah satu upaya untuk lebih mendorong perekonomiannya adalah mendorong pengembangan desa-desa dengan berbasis pada kearifan lokal, sumber daya alam dan keunikannya, sehingga dapat menjadi desa-desa yang inovatif dan kreatif. Sistem Informasi Geografis Pada Aplikasi Desa Pintar Berbasis Mobile dibuat untuk memberi kemudahan bagi pemerintah, masyarakat, wisatawan dan calon investor dalam menemukan informasi potensi desa seperti perikanan, perkebunan, perdagangan, wisata, budaya dan pelayanan umum. Sistem ini dibuat dengan menggunakan bahasa pemrograman PHP dan Java serta $M y S Q L$ sebagai basis datanya. Hasil dari penelitian ini adalah aplikasi pemetaan secara geografis berbasis mobile.
\end{abstract}

Kata Kunci: SIG, Desa Pintar, Biro Pusat Statistik, Mobile.

\section{PENDAHULUAN}

Kecamatan Andam Dewi terletak di Kabupaten Tapanuli Tengah Provinsi Sumatera Utara. Adapun keunggulan yang ada di kecamatan ini adalah berbagai potensi yang dapat dikembangkan untuk meningkatkan tingkat kesejahteraan masyarakatnya. Salah satunya adalah potensi geografisnya yang terletak di dataran rendah yang dikelilingi Laut dan Pegunungan sehingga pemandangan di daerah ini bervariasi, mulai dari Pesisir pantainya dan pegunungan. Dari segi budaya, kebiasaan atau kultur di daerah ini beragam mulai dari budaya batak, pesisir dan sebagainya. Dan masih banyak lagi potensipotensi yang ada di Kecamatan Andam Dewi ini, salah satu yang paling menonjol adalah pada segi perikanannya. Karena secara umum kebanyakan masyarakat bekerja sebagai nelayan (BPS Kabupaten Tapanuli Tengan, 2019).

Pemerintah Kabupaten Tapanuli Tengah dalam menyampaikan berbagai ragam informasi sebenarnya telah menggunakan website yang terdapat pada http://www.tapteng.go.id, namun informasi pada website tersebut masih sangat terbatas dan belum bisa mencakup sesuai dengan kebutuhan masyarakat atau pengunjung yang datang ke Kabupaten Tapanuli Tengah, hal inilah yang menyebabkan kebutuhan informasi bagi masyarakat belum dapat terpenuhi. Kurangnya informasi tentang potensi daerah yang disampaikan kepada masyarakat menjadi salah satu penyebab potensi daerah yang ada di Kabupaten Tapanuli Tengah kurang dikenal oleh masyarakat luas sehingga pangsa pasar potensi daerah pada Kabupaten Tapanuli Tengah tidak maksimal, di samping itu juga 
peluang untuk menggaet investor guna pengembangan usaha menjadi terbatas (Sasmito, 2017).

Selama ini, informasi pelayanan umum didapat dari Google Maps seperti Rumah Sakit, SPBU, sekolah, Bank dsb, namun belum disajikan informasi terutama hasil dari Badan Pusat Statistik (BPS). Oleh karena itu dibutuhkan suatu aplikasi yang bisa memancing datangnya investor atau wisatawan ke Tapanuli Tengah. Aplikasi ini memberikan infomasi antara lain lokasi potensi daerah, peta, titik koordinat, profil potensi daerah masing-masing, foto satelit dan data produk/hasil produksi setiap desa pada Kabupaten Tapanuli Tengah dapat dirancang dengan menggunakan sebuah visualisasi yang lebih menarik.

Aplikasi yang dibangun disebut dengan aplikasi desa pintar (Smart Village) dan akan menunjang kegiatan masyarakat, wisatawan, investor, petani, nelayan dan para pengusaha kecil. Manfaat lain dirasakan oleh pemerintah setempat, karena dengan aplikasi tidak membutuhkan anggaran yang besar untuk promosi daerahnya ke luar daerah dan ke luar negeri (Supriadi, Fadli H, \& Malik, 2016).

\section{KAJIAN LITERATUR}

\section{Sistem Informasi Geografis}

Sistem Informasi Geografis (SIG), atau dalam bahasa Inggris lebih dikenal dengan Geographic Information Sistem, adalah suatu sistem berbasis komputer yang digunakan untuk mengolah dan menyimpan data. Sistem informasi geografis adalah paket perangkat lunak yang terintegrasi khusus yang dirancang untuk digunakan bersamaan dengan data geografis yang mampu melakukan berbagai tugas komprehensif penanganan data. Tugas ini meliputi input data, penyimpanan, pencarian dan output, selain itu juga dapat melakukan berbagai macam proses deskriptif dan analisis (Naibaho, 2016).

\section{Aplikasi}

Menurut Kamus Besar Bahasa Indonesia, Aplikasi adalah penerapan dari rancang sistem untuk mengolah data yang menggunakan aturan atau ketentuan bahasa pemrograman tertentu. Aplikasi adalah suatu program komputer yang dibuat untuk mengerjakan dan melaksanakan tugas khusus dari user (pengguna). Menurut Hendrayudi, Aplikasi adalah kumpulan perintah program yang dibuat untuk melakukan pekerjaan-pekerjaan tertentu. Menurut Rachmad Hakim S, Aplikasi adalah perangkat lunak yang digunakan untuk tujuan tertentu, seperti mengolah dokumen, mengatur windows, permainan, dan sebagainya (Aprianto, Wulandari, \& Hafifah, 2018).

\section{Desa Pintar (Desa Inovatif dan Kreatif)}

Desa Pintar adalah desa yang mampu memanfaatkan sumber daya desa dengan cara baru. Pengembangan desa pintar memerlukan peran serta aktif dari berbagai elemen, yaitu unsur- unsur kelembagaan desa dan daerah, akademisi (perguruan tinggi), pengusaha, perbankan, dan lembaga penelitian dan pengembangan. Konsep program Desa Inovasi adalah bagaimana memberdayakan masyarakat desa dan bagaimana memanfaatkan potensi lokal melalui pemanfaatan Iptek untuk menciptakan masyarakat desa yang lebih sejahtera (Academician, Business, Government, and Community) seperti yang diamanatkan dalam UU No.6 Tahun 2014.

\section{Google Maps}

Google Maps adalah sebuah jasa peta Globe Virtual gratis dan online yang disediakan oleh Google, google maps ini dapat diakses http://maps.google.com/. Google Map API merupakan aplikasi interface yang dapat diakses lewat Javascript agar Google Map dapat ditampilkan pada halaman web yang sedang dibangun. Untuk dapat mengakses Google Map, harus dilakukan pendaftaran Api Key terlebih dahulu dengan data pendaftaran berupa nama domain web yang dibangun. Google Maps API merupakan aplikasi interface yang dapat diakses lewat Javascript agar Google Maps dapat ditampilkan pada sebuah Smartphone. Untuk dapat menggunakan google maps API maka dibutuhkan API Keys berupa script yang harus ditambahkan ke dalam baris Java Android Script untuk menampilkan android map (Austin, 2016).

\section{METODOLOGI PENELITIAN}

\section{Analisis Kebutuhan}

Analisis kebutuhan dilakukan dengan cara pengambilan data sekunder dari Badan Pusat Statistik (BPS) Tapanuli Tengah Tahun 2019, yaitu Kecamatan Andam Dewi salah satu sample data yang ditampilkan seperti tabel 1 berikut:

Tabel 1. Informasi Objek Wisata

\begin{tabular}{|l|c|c|}
\hline \multirow{2}{*}{\multicolumn{1}{|c|}{ Desa/Kelurahan }} & \multicolumn{2}{c|}{ Objek Wisata } \\
\cline { 2 - 3 } & Jumlah & Nama \\
\hline Ladang Tengah & - & - \\
\hline Uratan & - & - \\
\hline Lobu Tua & 1 & Pantai Kahona \\
\hline Bondarsihudon I & - & - \\
\hline Bondarsihudon II & - & - \\
\hline Rina Bolak & - & - \\
\hline Sosor Gonting & - & - \\
\hline Sirami-ramian & - & - \\
\hline Pangaribuan & - & - \\
\hline Sijungkang & - & - \\
\hline Sogar & - & - \\
\hline Sigolang & - & Pantai Indah Sitiris- \\
\hline Sitiris-tiris & 1 & \\
\hline
\end{tabular}




\begin{tabular}{|l|c|c|}
\hline & & tiris \\
\hline Sawah Lamo & - & - \\
\hline Total & $\mathbf{2}$ & \\
\hline
\end{tabular}

Sumber: https://tapanulitengahkab.bps.go.id/

\section{Desain Sistem}

Analisis interaksi yang dilakukan pengguna terhadap Sistem Informasi Geografis Pada Aplikasi Desa Pintar Berbasis Mobile di Tapanuli Tengah dapat digambarkan dengan menggunakan use case diagram seperti gambar berikut:

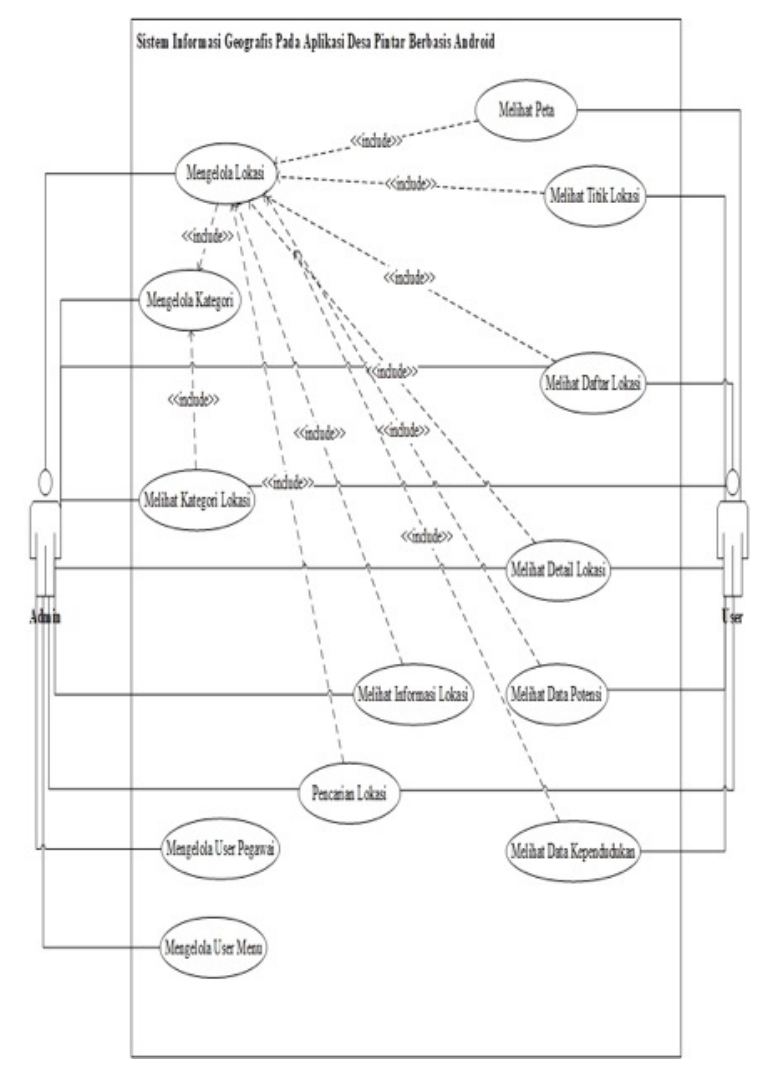

Gambar 1. Use Case Diagram

\section{Analisis Fungsional}

Analisis fungsional adalah tahapan yang menggambarkan fungsi-fungsi dari sistem yang dibangun. Ada beberapa di antaranya adalah Activity Diagram Admin, Activity Diagram Pegawai dan Activity Diagram User.

\section{Activity Diagram Admin}

Proses dimulai dengan admin masuk ke halaman Login. Jika login gagal maka admin akan mengulang proses login tersebut. Jika login sukses, maka admin masuk ke halaman dashboard admin, kemudian Admin dapat mengelola semua data seperti gambar 2 dan selanjutnya proses selesai.

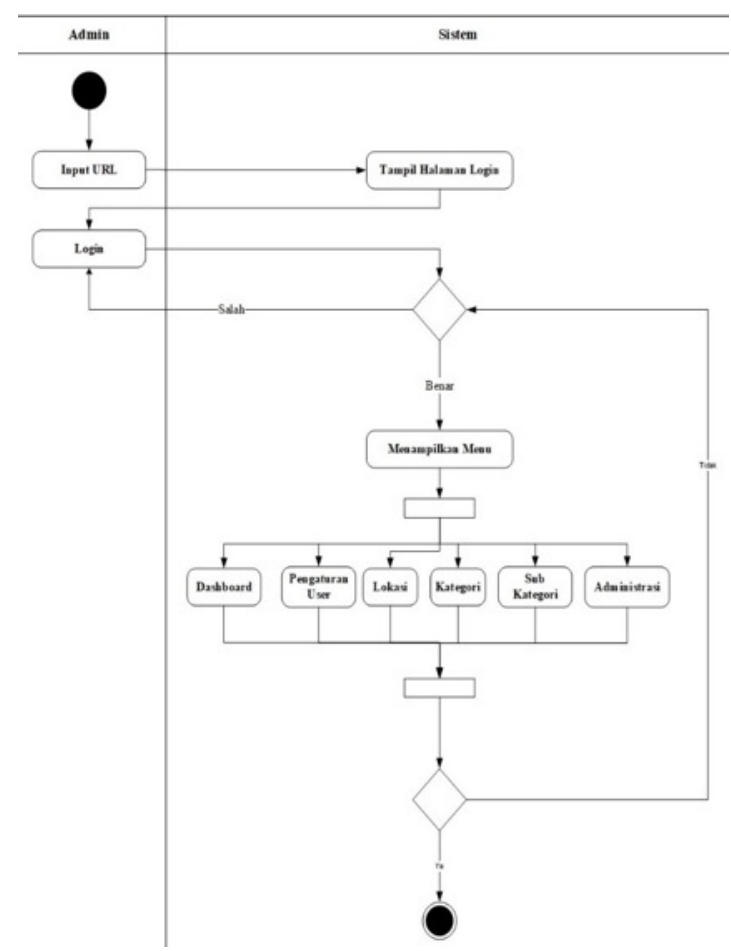

Gambar 2. Activity Diagram Admin

2. Activity Diagram Pegawai

Proses dimulai dengan pegawai masuk ke halaman Login. Jika login sukses, maka pegawai akan masuk ke halaman dashboard pegawai. Jika login gagal maka pegawai akan mengulang proses login tersebut. Pegawai dapat mengelola semua data seperti gambar 3 dan selanjutnya proses selesai.

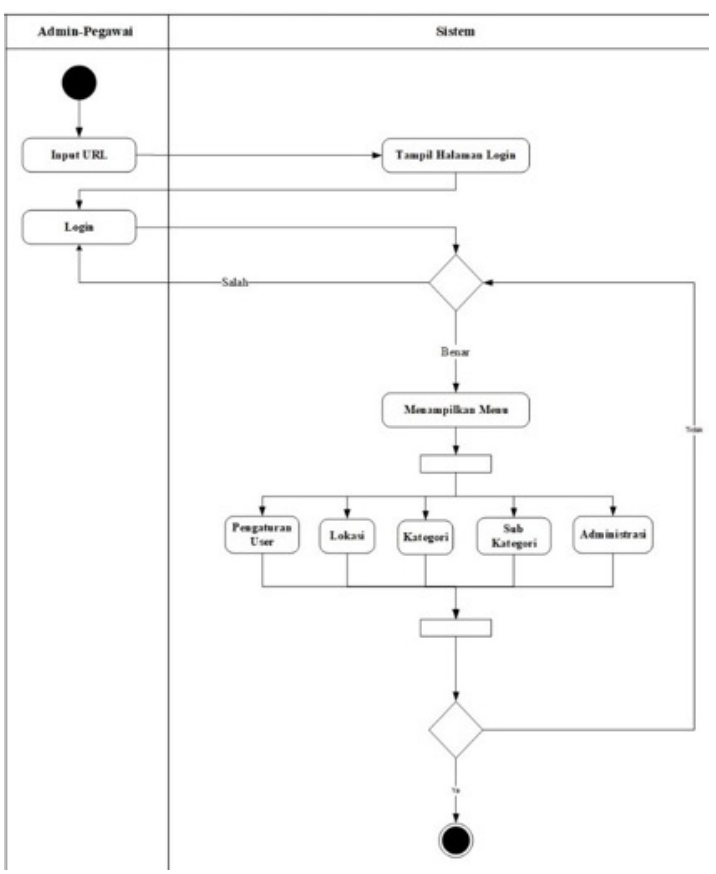

Gambar 3. Activity Diagram Pegawai 
3. Activity Diagram User

Proses dimulai dengan aplikasi yang telah dibuka oleh User, kemudian muncul splash screen, setelah itu masuk ke halaman dashboard (halaman utama) dan menu. Data yang telah tersedia dapat dilihat User berupa lokasi pelayanan umum, potensipotensi daerah, produksi daerah seperti gambar 4 dan selanjutnya proses selesai.

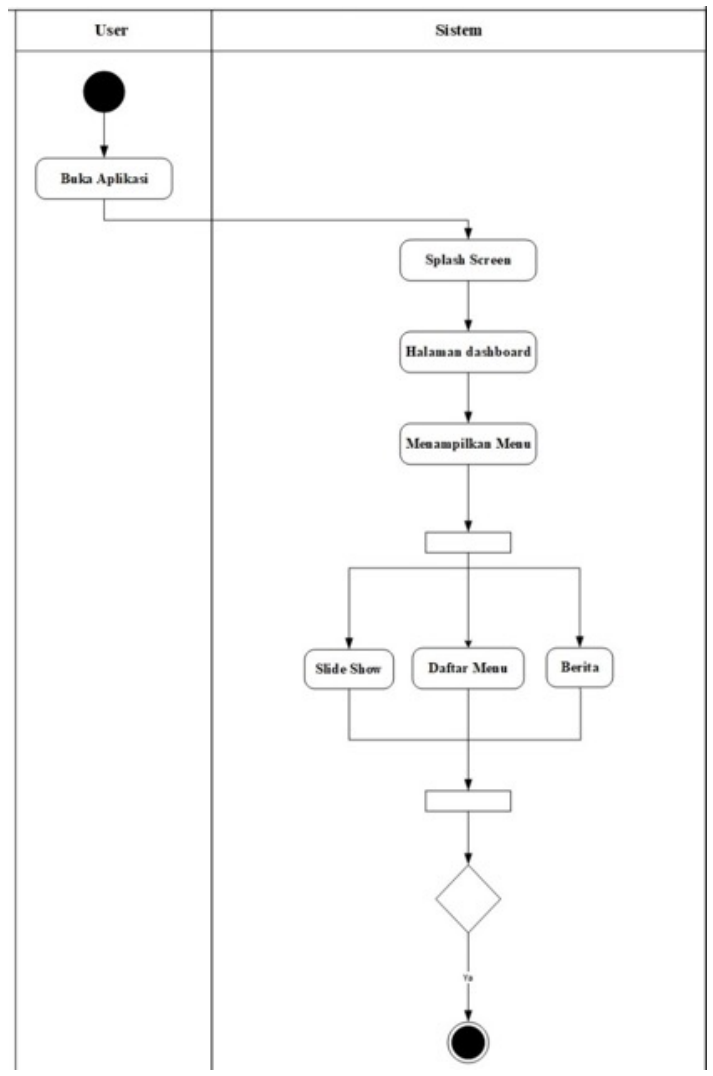

Gambar 4. Activity Diagram User

\section{HASIL DAN PEMBAHASAN}

Implementasi Login Admin

Implementasi Login Admin menggunakan email account seperti gambar 5 di bawah ini.

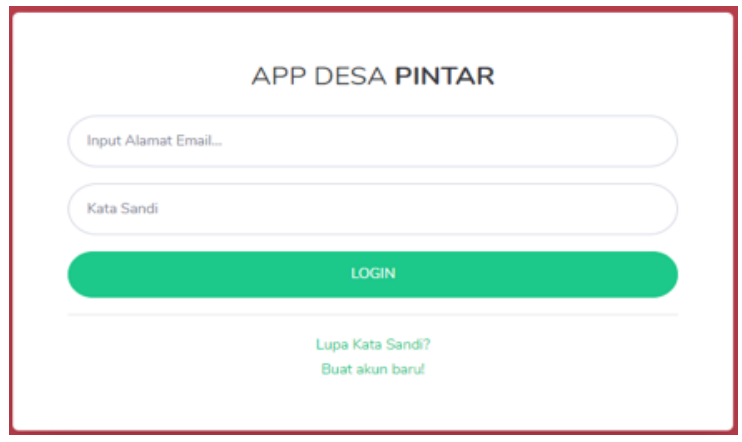

Gambar 5. Login Admin
Admin atau pegawai juga dilengkapi fitur lupa kata sandi. Admin memiliki hak penuh terhadap aplikasi yang dibuat sedangkan pegawai diberikan batasan hak akses. Bagi pegawai dan user yang belum memiliki akun, maka tersedia link "buat akun baru", seperti Gambar 6 berikut.

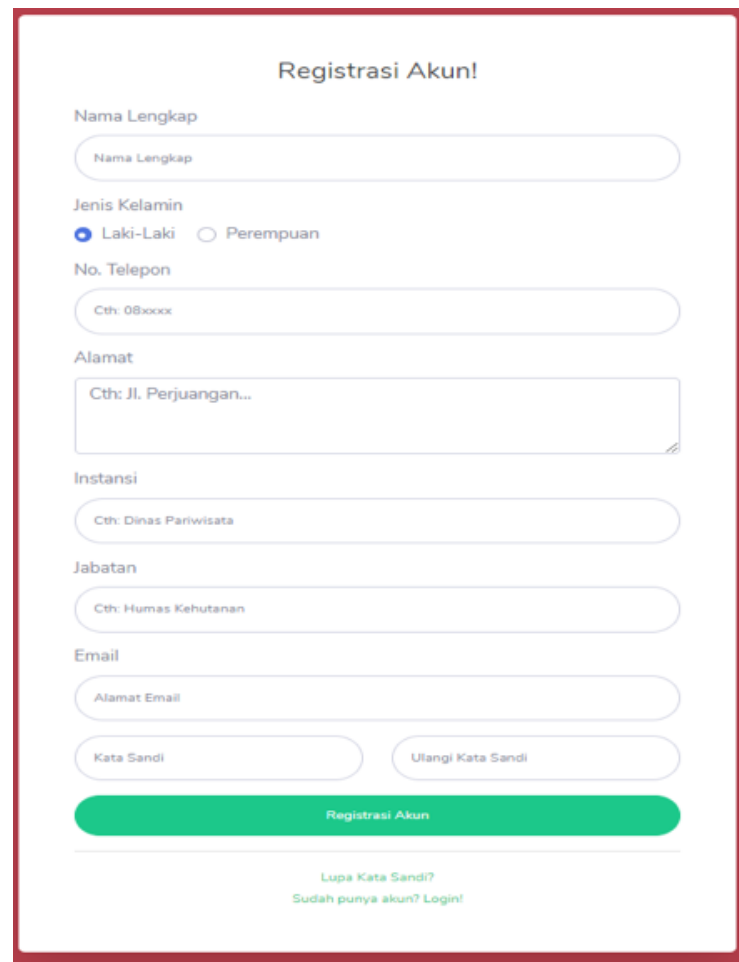

Gambar 6. Registrasi Akun

\section{Implementasi Dashboard Admin dan Pegawai}

Halaman ini merupakan halaman seorang administrator yang berhasil login untuk mengelola isi konten sistem ini. Gambar 7 adalah dashboard untuk pegawai dari dinas-dinas terkait, sedangkan pada gambar 8 adalah dashboard untuk Admin

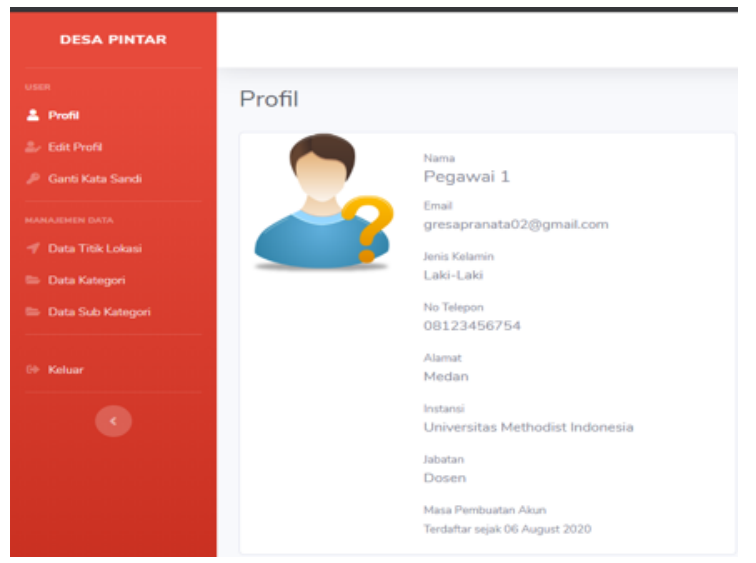

Gambar 7. Dashboard Pegawai 


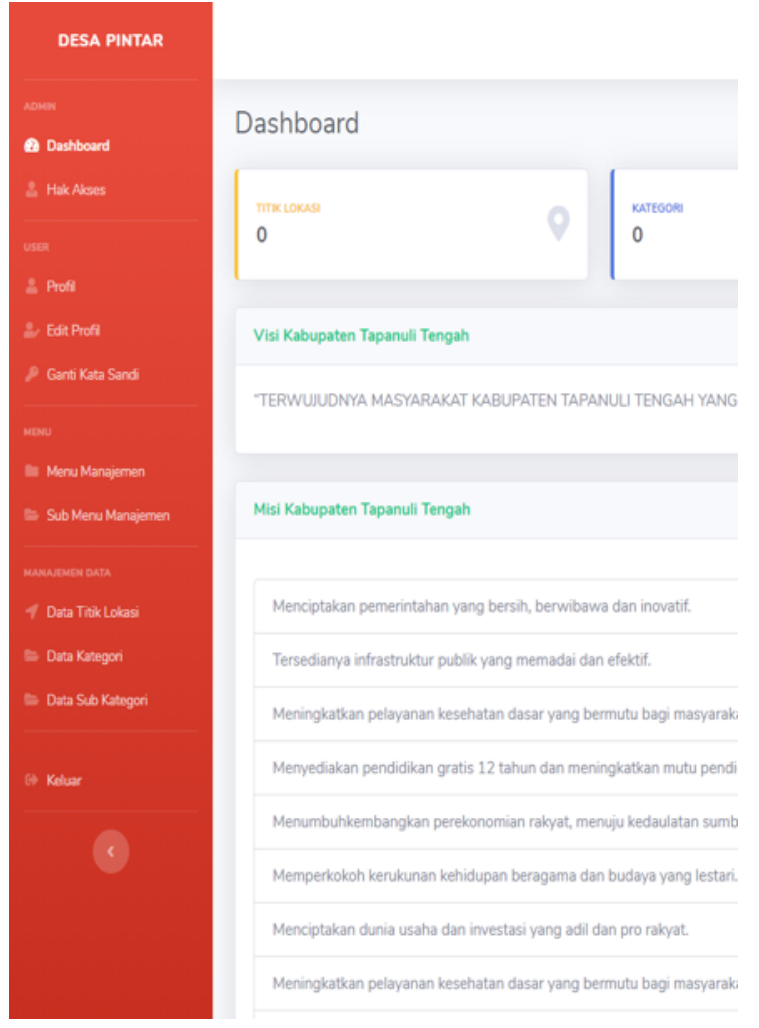

Gambar 8. Dashboard Admin

\section{Implementasi Titik Lokasi}

Halaman titik lokasi merupakan halaman yang berfungsi untuk pengelolaan titik lokasi. Admin dapat menambah, mengubah, menghapus dan melihat detail titik lokasi. Data yang tampil pada halaman ini adalah data sesuai user yang sedang login. Selain itu admin juga dapat melakukan pencarian lokasi yang telah di-input sebelumnya. Cara kerjanya adalah jika ingin menambah lokasi baru, klik tombol "tambah lokasi", jika ingin mengedit lokasi yang ada, klik "edit" pada bagian aksi, untuk menghapus lokasi, klik "hapus" pada bagian aksinya, sedangkan untuk melihat detail lokasi, klik "lihat" pada bagian aksi seperti yang tampil pada Gambar 9 berikut ini.

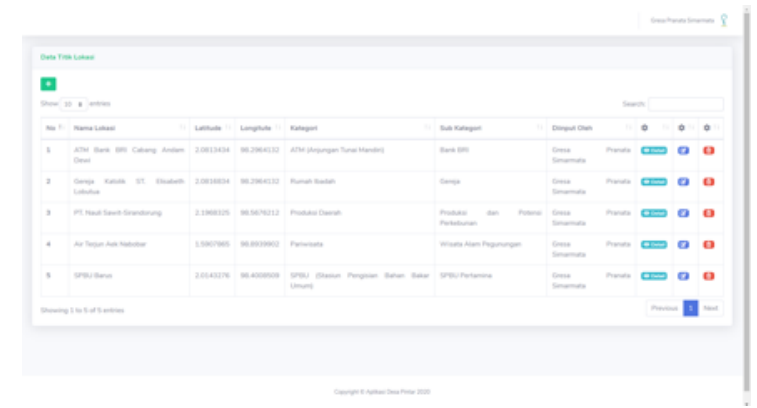

Gambar 9. Implementasi Titik Lokasi

\section{Tampilan User (Mobile)}

Aplikasi yang digunakan oleh user adalah aplikasi yang digunakan oleh masyarakat awam (pengguna) melalui Smartphone Android berbasis mobile. Pada aplikasi ini terdiri dari beberapa halaman, di antaranya adalah sebagai berikut:

1. Implementasi Splash Screen

Merupakan halaman pembuka untuk aplikasi berbasis mobile. Manfaat halaman loding ini adalah sebagai pengatur sebelum menu utama terbuka seperti yang tampak pada Gambar 10 berikut ini.

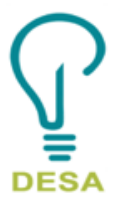

DESA PINTAR

Gambar 10. Implementasi Splash Screen

2. Implementasi Dashboard User

Pada halaman utama ini berisi fitur-fitur dari aplikasi yang dapat digunakan oleh pengguna Smartphone Android, di antaranya: pilihan beberapa menu, berita dan pencarian seperti yang tampak pada Gambar 11 berikut ini.

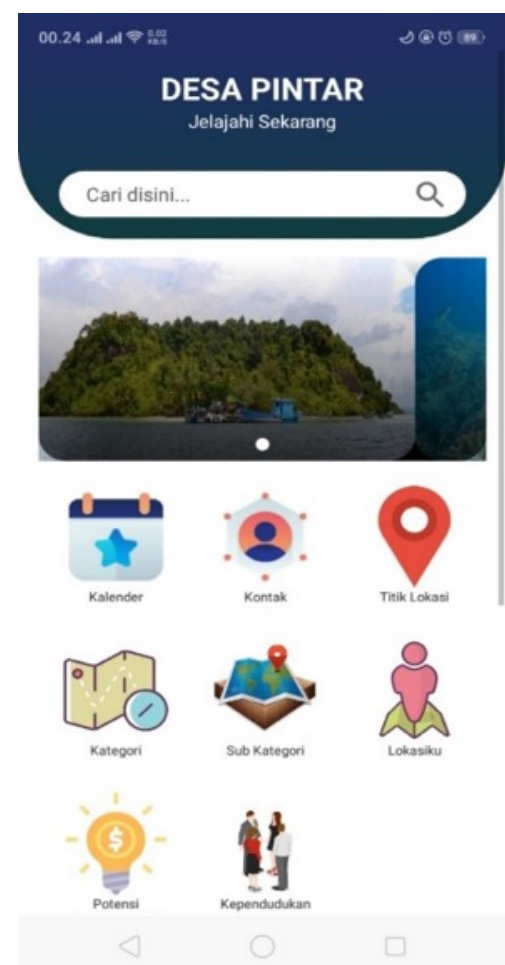

Gambar 11. Implementasi Dasboard User 
3. Implementasi Titik Lokasi

Untuk halaman titik lokasi ini akan menampilkan list-list titik lokasi berdasarkan kategori dan subkategori yang dimaksud. Kemudian dihalaman ini akan menampilkan peta dan informasi lokasi dan alamat seperti Gambar 12 berikut ini.

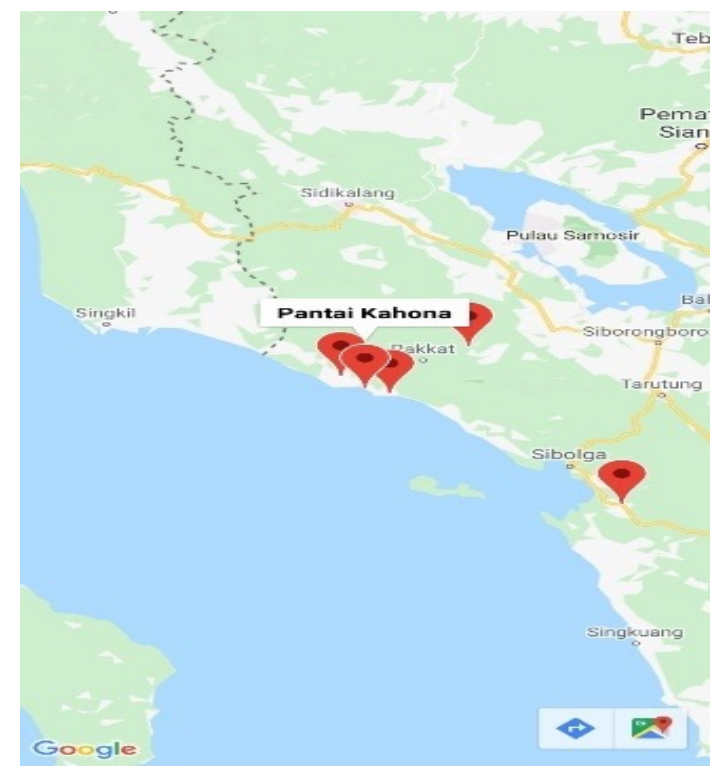

Gambar 12. Implementasi Titik Lokasi

4. Implementasi Potensi

Ini adalah halaman menu potensi untuk tampilan user. Halaman menu potensi merupakan halaman yang menampilkan informasi-informasi potensial yang ada pada Kecamatan Andam Dewi. Informasi-informasi yang dimaksud seperti, pariwisata, perdagangan, perkebunan dan rumah ibadah. Tampilan implementasi potensi dapat dilihat pada Gambar 13 berikut ini.

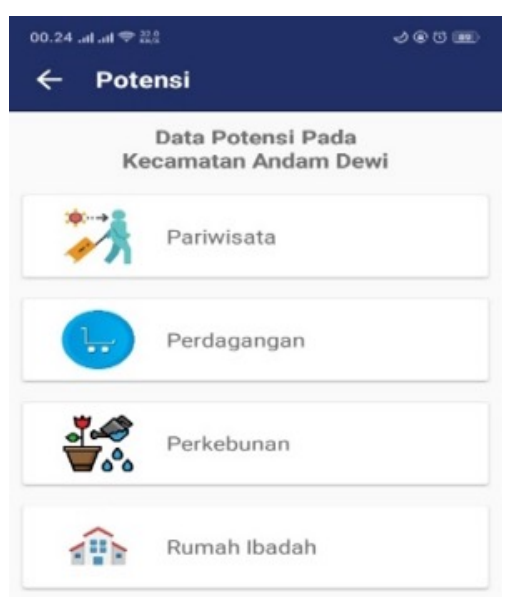

Gambar 13. Implementasi Potensi
5. Implementasi Pariwisata

Tampilan pada implementasi ini adalah informasi pariwisata yang berada di Kecamatan Andam Dewi. Sumber data pariwisata diperoleh dari Badan Pusat Statistik (BPS).

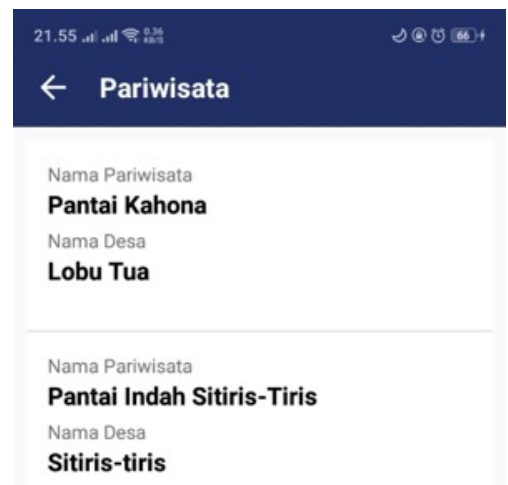

Gambar 14. Implementasi Pariwisata

\section{KESIMPULAN}

Berdasarkan hasil perancangan dan pengujian yang dilakukan, maka diambil kesimpulan bahwa pemetaan titik lokasi berdasarkan kategori, baik potensi daerah, produksi daerah dan pelayanan umum di Kecamatan Andam Dewi, Kabupaten Tapanuli Tengah dapat dipetakan berdasarkan data yang dikeluarkan oleh Biro Pusat Statistik (BPS). Dengan menggunakan layanan web service berupa jaringan internet, aplikasi ini dapat tampil di dua platform berbeda, yaitu web dan perangkat mobile (Smartphone Android)

\section{DAFTAR PUSTAKA}

Aprianto, R., Wulandari, \& Hafifah, N. (2018). Pengembangan Aplikasi Web Mobile Penjadwalan Tugas Aparatur Desa Untuk Meningkatkan Layanan Masyarakat. Jurnal Teknologi Komputer Dan Sistem Informasi, 01(03), 81-86. Retrieved from http://ojs.stmikpringsewu.ac.id/index.php/jtksi/a rticle/view/663

Austin, R. (2016). Sistem Informasi Geografis Pemetaan Pelayanan Umum Di Palembang Berbasis Android. UIN Raden Fatah Palembang.

BPS Kabupaten Tapanuli Tengan. (2019). Kabupaten Tapanuli Tengah dalam Angka 2019.

Naibaho, J. F. (2016). Pemetaan Informasi Sarana Kesehatan Masyarakat Serta Penyajian Rute Terdekat Menuju Lokasi Sarana Pelayanan Kesehatan Pada Wilayah Kota Berbasis Online. Prosiding Seminar Nasional Pendidikan Teknik Informatika (SENAPATI 2016), 181-187. 
Sasmito, G. W. (2017). Penerapan Metode Waterfall Pada Desain Sistem Informasi Geografis Industri Kabupaten Tegal. Jurnal

Informatika:Jurnal Pengembangan IT (JPIT), 2(1), 6-12.

Supriadi, A., Fadli H, M. N., \& Malik, K. (2016). Membangun Sistem Smart Village Untuk Menciptakan Ekonomi Masyarakat Desa Mandiri Di Desa Alastengah Kecamatan Paiton Kabupaten Probolinggo Berbasis Android. Prosiding SENTIA 2016 - Politeknik Negeri Malang, 8, 65-68. 